DOI: 10.17707/AgricultForest.62.4.05

\begin{abstract}
Nikola PACINOVSKI, Vladimir DZABIRSKI, Dimitar NAKOV, Koco PORCU, Metodija TRAJCHEV, Goce CILEV, Elena JOSHEVSKA ${ }^{1}$
\end{abstract}

\title{
EFFECTS OF NON-GENETIC FACTORS ON DAILY MILK PRODUCTION IN AWASSI BREED OF SHEEP IN MACEDONIA
}

\section{SUMMARY}

Several basic - fixed factors on daily milk yield have been examined in total of 132 Awassi breed sheep, during two - year production period (2011 and 2012). The examination includes the following factors: lactation number, lactation type, date of milk recording, number of newborn lambs, month or year of milk recording and length of suckling period. Their influence on individual milk yield measured in morning, afternoon and evening milking, total daily milk yield and percentage of milk fat has been examined. A total of 904 lactation tests in sheep, aged from first to eight lactation were included in the research. All data were analyzed using a multi-factorial fixed model.

The influence of certain factors was studied using the F-test. Analyzes were made using the SSPS set of programs. Most of the factors (number of lactation, date of milk recording, month or year of milk recording and length of suckling period), except the number of newborn lambs or fertility, had a highly significant influence $(\mathrm{P}<0.01)$ on daily milk production (milk from the morning, afternoon and evening and total amount of milk, as well as \% of milk fat) in examined breed of sheep. Highest daily milk production was determined among sheep in sixth lactation and lowest among those in eighth lactation. On the other hand, the highest percentage of milk fat was determined among sheep in seventh lactation and the lowest among those in second lactation.

Three types of lactation curve were identified in examined sheep of which most abundant is the one with one peak. These data suggest that the Awassi breed, as breed with high milk production, retains the level of high and standard milk production to an older age, which is a prerequisite for profitable and sustainable livestock production.

Keywords: Awassi, daily milk yield, influence of factors, lactation curve

\section{INTRODUCTION}

Awassi breed of sheep as local fat-tailed sheep from Middle East is dairy breed with unique physiological characteristics. Due to its high production of

\footnotetext{
${ }^{1}$ Nikola Pacinovski, (corresponding author: npacinovski@yahoo.com), Cyril and Methodius University in Skopje, Institute of Animal Science, Skopje, MACEDONIA, Vladimir Dzabirski, Dimitar Nakov, Koco Porcu, Metodija Trajchev, Cyril and Methodius University, Faculty of Agricultural Sciences and Food, Skopje, MACEDONIA, Goce Cilev, St. Kliment Ohridski University, Veterinary Faculty, Bitola, MACEDONIA, Elena Joshevska, St. Kliment Ohridski University, Faculty of Biotechnical Sciences, Bitola, MACEDONIA.

Paper presented at the $7^{\text {th }}$ International Scientific Agricultural Symposium "AGROSYM 2016".

Notes: The authors declare that they have no conflicts of interest. Authorship Form signed online.
} 
milk, Awassi breed is used as parent breed during advancing of milk production in many local breeds of sheep and breeds with low milk production from Asian and African continent (Gursoy et al., 1988).

The original non-selective type of this breed had extremely low production traits with low milk yield, which makes it equal with indigenous breeds of sheep in Macedonia (ovchepolian and sharplanina sheep). However, through systematic genealogic selection for high milk yield and infusion of blood from East-Friesian sheep with intensive diet, it was created a type of this breed, with high milk production. This breed of sheep is imported in Macedonia in 1969 from Israel. Its existence of many years in this region demonstrates successful acclimatization, with high capabilities for production of sheep milk. It is imported in order to increase the milk yield in domestic breed of sheep, with low milk production, through the method of crossbreeding.

According to data from Food and Veterinary Agency, Department for identification and registration of livestock, of the total number of sheep in Macedonia (around 700.000 sheep), the percentage of sheep with blood of Awassi breed (purebred and crossbreeds) is about 5\% (35.000 sheep).

Having regard to the importance of regular and accurate individual milk recording, during selection of dairy sheep population, this work is an attempt to study the basic or fixed factors that affect the daily milk yield in Awassi breed of sheep. In other words, the purpose of this research was to establish the extent and manner in which basic (fixed) factors affect the amount of milk measured during the test day in Awassi breed of sheep.

\section{MATERIAL AND METHODS}

Tests were performed in total of 132 Awassi sheep, located on a farm in the village Gradishte, in Kumanovo surrounding. The sheep ranged in age from second to eighth lactation. Individual milk yield in sheep is tested once a month using A4 method, during a period of two lactation years (2011 and 2012). During the test day, milk yield was tested for all milking (morning, afternoon, evening) whose number depends on the period of lactation.

Test of milk production was performed from the moment of weaned the lambs until drying of sheep. A total of 8 milk tests were realized. The basic variable factors during the test were: individual milk yield in sheep measured in the morning, afternoon and evening milking, total daily milk yield and percentage of milk fat.

Each of these factors was examined on total of 904 test days or samples for total sheep i.e. lactations. The influence of several basic or fixed factors was examined on the following so called variable factors: date of birth of lambs, lactation number, month of milk test, percentage of milk fat, number of newborn lambs.

The statistical analysis of data is performed according to the following fixed LS - model: 
Where:

$$
Y_{\mathrm{ijklmn}}=\mu+L_{i}+T_{j}+T D_{k}+N L_{l}+M Y_{m}+S P_{n}+e_{\mathrm{ijklmn}}
$$

$Y$ - determination of one of five described variable factors or traits,

$\mu$-average for that trait,

$L_{i}-$ effect of i-th lactation $(i=1,2,3,5,6,7,8)$,

$T_{j}$ - effect of $\mathrm{j}$-th type of lactation curve $(j=1,2,3)$,

$T D_{k}$ - effect of k-th test day $(k=1,2,3,4,5,6,7,8,9)$,

$N L_{l}$ - effect of 1-th number of newborn lambs $(l=1,2)$,

$M Y_{m}-$ effect of $\mathrm{m}-$ th month of milk yield measuring $(m=1, \ldots .16)$,

$S P_{n}$ - effect of prolongation of suckling period on $n$-th sheep for lactation 1

measured as linear regression and

$e_{\mathrm{ijklmn}}-$ represents residual for record of effects that are not observed.

The statistical significance of effects was determined using F-test.

\section{RESULTS AND DISCUSSION}

Average production

Average value of the five examined traits i.e. factors, are presented in Table 1. The milk yield is reduced from 0.591 in the morning, to 0.401 in the afternoon and 0.39 in the evening. The average total daily milk yield was 1.361 with fat content of $7.59 \%$.

These average indicators for productivity characterize Awassi breed of sheep, as a typical representative of specialized breeds of sheep for milk.

Table 1. Estimates of LS-analyses of the daily milk yield of the Awassi ewes

\begin{tabular}{|c|c|c|c|c|}
\hline \multirow{2}{*}{ Trait } & \multirow{2}{*}{ Mean } & \multirow{2}{*}{ SE } & \multicolumn{2}{|c|}{ 95\% Confidence interval } \\
\cline { 4 - 5 } & & & Lower Bound & Upper Bound \\
\hline Milk yield - morning, 1 & 0.594 & 0.027 & 0.541 & 0.646 \\
\hline Milk yield - mid day, 1 & 0.406 & 0.017 & 0.371 & 0.440 \\
\hline Milk yield - evening, 1 & 0.393 & 0.020 & 0.353 & 0.433 \\
\hline Milk yield - total, 1 & 1.359 & 0.053 & 1.255 & 1.463 \\
\hline Fat, \% & 7.587 & 0.120 & 7.352 & 7.822 \\
\hline
\end{tabular}

Influence of different factors on milk production

The following factors have significant influence during the examination:

- Number of lactation, which represents the influence of age,

- Number of test day, which represent the stage of lactation,

- Month and year of measurement, that represent the average or moderate influence on diet, climate and breeding conditions and

- Suckling period, which represents the stage of lactation, after the start of milk test (Table 2). 
Table 2. Influence of the effects on the daily milk yield traits, F-statistics

\begin{tabular}{|c|c|c|c|c|c|c|}
\hline Source & Df & $\begin{array}{c}\text { Milk } \\
\text { morning }\end{array}$ & $\begin{array}{l}\text { Milk } \\
\text { midday }\end{array}$ & $\begin{array}{c}\text { Milk } \\
\text { evening }\end{array}$ & Milk daily & Fat, \% \\
\hline Lactation & 6 & $3.151^{* *}$ & $3.056^{* * *}$ & $1.858^{\mathrm{ns}}$ & $3.929^{* * *}$ & $0.602^{\mathrm{ns}}$ \\
\hline Type & 2 & $5.517^{* *}$ & $2.537^{\mathrm{ns}}$ & $3.343^{*}$ & $5.276^{* *}$ & $0.182^{\mathrm{ns}}$ \\
\hline Test day & 8 & $2.945^{* *}$ & $3.868^{* * *}$ & $2.758^{* * *}$ & $5.180^{* * * *}$ & $1.100^{\mathrm{ns}}$ \\
\hline No of lambs & 1 & $1.836^{\mathrm{ns}}$ & $2.891^{\mathrm{ns}}$ & $0.608^{\mathrm{ns}}$ & $0.002^{\mathrm{ns}}$ & $0.015^{\mathrm{ns}}$ \\
\hline Month/year & 15 & $10.088^{* * *}$ & $5.519^{* * *}$ & $6.412^{* * *}$ & $4.617^{* * *}$ & ${ }^{35.563^{* *}}$ \\
\hline $\begin{array}{c}\text { Suckling } \\
\text { period }\end{array}$ & 1 & $11.708^{* * *}$ & $13.507^{* * *}$ & $7.061^{* * *}$ & $15.412^{* * *}$ & $0.308^{\mathrm{ns}}$ \\
\hline R Squared & & 0.682 & 0.683 & 0.508 & 0.705 & 0.673 \\
\hline
\end{tabular}

*ns - non significant, * $-\mathrm{P}<0.05 ; * *-\mathrm{P}<0.01 ; * * *-\mathrm{P}<0.001$

It seems that the number of newborn lambs does not affect the variation of daily milk production, whereas the type of lactation curve only affects some of the measurements of daily milk yield. The influence of all these effects is explained in detail below.

When the selected factors determine $50-70 \%$ of the variation of analyzed traits, then the same can be used for future studies for construction of models for genetic evaluations.

\section{Influence of number of lactation}

With the increase of age, milk yield slightly increases from first $(0,5561)$ to third lactation $(0,6181)$ during morning milking, decreases in fifth lactation ( starting from the end of fourth lactation) and reaches a maximum during sixth lactation, after which slightly reduces to 0,451 , during eighth lactation.

Similar dynamics was determined for afternoon and evening milk yield and for total milk yield in test day (Table 3 ).

Table 3. Effect of lactation number on the daily milk yield traits, LS-means $\pm \mathrm{SE}$

\begin{tabular}{|c|c|c|c|c|c|}
\hline Lact & Milk morning & Milk midday & Milk evening & Milk daily & Fat, \% \\
\hline 1 & $0.556 \pm 0.037$ & $0.378 \pm 0.024$ & $0.389 \pm 0.028$ & $1.274 \pm 0.073$ & $7.551 \pm 0.166$ \\
\hline 2 & $0.593 \pm 0.029$ & $0.377 \pm 0.019$ & $0.389 \pm 0.022$ & $1.325 \pm 0.058$ & $7.455 \pm 0.131$ \\
\hline 3 & $0.618 \pm 0.035$ & $0.425 \pm 0.023$ & $0.418 \pm 0.027$ & $1.426 \pm 0.070$ & $7.564 \pm 0.160$ \\
\hline 5 & $0.588 \pm 0.041$ & $0.389 \pm 0.027$ & $0.400 \pm 0.032$ & $1.344 \pm 0.083$ & $7.599 \pm 0.187$ \\
\hline 6 & $0.707 \pm 0.035$ & $0.458 \pm 0.023$ & $0.418 \pm 0.027$ & $1.549 \pm 0.070$ & $7.596 \pm 0.160$ \\
\hline 7 & $0.646 \pm 0.040$ & $0.448 \pm 0.026$ & $0.449 \pm 0.031$ & $1.533 \pm 0.080$ & $7.765 \pm 0.182$ \\
\hline 8 & $0.448 \pm 0.074$ & $0.364 \pm 0.048$ & $0.286 \pm 0.055$ & $1.063 \pm 0.142$ & $7.578 \pm 0.321$ \\
\hline
\end{tabular}


These results show that Awassi sheep can be successfully used as heads for production, continuously, in order to preserve sufficient milk productivity. Considering that these examinations are preliminary, we suggest such examinations to be realized in greater number in future, for multiple age groups and classes, in order to achieve more accurate and more reliable statistical analysis. The dynamics of the percentage of milk fat has the same tendency as milk yield i.e. an increase from $7.5 \%$ during first to $7.8 \%$ during seventh lactation, but it seems that differences between age groups are not significant for this trait. This is confirmed by insignificant effect of the factor, number of lactation in ANOVA (Table 2).

Simultaneous increase of milk production and content of fat with the increase of age, although contradictory, may be a result of parallel development of mammary gland, giving the ability to maintain both high productivity and quality of milk.

The results show that the influence of age is important while setting appropriate models for genetic evaluation. The limited number of sheep in flock would require inclusion of as many heads and similar data for all lactations, in order to achieve higher accuracy in the process of evaluation.

Pacinovski et al. (2014) also found significant influence of lactation on above mentioned traits (morning, afternoon and evening milk) in Awassi breed of sheep.

\section{Influence of the type of lactation curve}

The obtained results of analyzed data show the existence of three types of lactation curves in examined Awassi sheep: first type (11) with one pik value, second type (21) also with one pik value and third type (22) with two pik values, during lactation. However, in tested flock, in most cases (around 350 measurements) are sheep of type 21 (Table 4).

Highest milk yield is determined in the second type, with two pik values (22), whereas the most common type (21) shows average productivity.

Such scheme of influence was observed at all traits of milk production: morning, afternoon, evening and total amount of milk for the test day (Table 5).

When determining the statistical influence, significant influence of this factor (type of lactation curve) was determined during morning and evening milking.

Insignificant influence of the type of lactation was determined on the percentage of fat. Obtaining and providing more data will probably be necessary to extract more reliable and more categorical data. Overall, it seems that the effect of the lactation type is not very important as a factor that should be included in the model, but it is important as an indication or criteria for future observation and possible eventual selection. 
Table 4. Number of milk yield tests per trait

\begin{tabular}{|c|c|c|c|c|c|c|c|}
\hline Factor & Code & No & Morning & Midday & Evening & Daily & Fat $\%$ \\
\hline Total & & 399 & 382 & 372 & 394 & 395 & 394 \\
\hline \multirow{7}{*}{ Lactation } & 1 & 80 & 76 & 74 & 79 & 80 & 80 \\
\hline & 2 & 131 & 126 & 123 & 128 & 128 & 127 \\
\hline & 3 & 73 & 69 & 66 & 73 & 73 & 73 \\
\hline & 5 & 35 & 33 & 33 & 34 & 34 & 34 \\
\hline & 6 & 38 & 37 & 36 & 38 & 38 & 38 \\
\hline & 7 & 34 & 34 & 33 & 34 & 34 & 34 \\
\hline & 8 & 8 & 7 & 7 & 8 & 8 & 8 \\
\hline \multirow{3}{*}{ Type } & 11 & 25 & 21 & 21 & 22 & 22 & 22 \\
\hline & 21 & 359 & 346 & 337 & 357 & 358 & 357 \\
\hline & 22 & 15 & 15 & 14 & 15 & 15 & 15 \\
\hline \multirow{9}{*}{ Test-day } & 1 & 55 & 55 & 55 & 55 & 55 & 55 \\
\hline & 2 & 55 & 55 & 55 & 55 & 55 & 55 \\
\hline & 3 & 55 & 55 & 55 & 55 & 55 & 55 \\
\hline & 4 & 55 & 55 & 55 & 54 & 55 & 55 \\
\hline & 5 & 51 & 51 & 49 & 51 & 51 & 51 \\
\hline & 6 & 47 & 47 & 44 & 47 & 47 & 47 \\
\hline & 7 & 41 & 31 & 30 & 40 & 40 & 40 \\
\hline & 8 & 25 & 20 & 16 & 24 & 24 & 24 \\
\hline & 9 & 15 & 13 & 13 & 13 & 13 & 12 \\
\hline \multirow{2}{*}{ No lambs } & 1 & 332 & 318 & 310 & 327 & 328 & 327 \\
\hline & 2 & 67 & 64 & 62 & 67 & 67 & 67 \\
\hline \multirow{17}{*}{$\begin{array}{c}\text { Month } \\
\text { and } \\
\text { year of test }\end{array}$} & 12012 & 10 & 10 & 10 & 10 & 10 & 10 \\
\hline & 22011 & 15 & 15 & 15 & 15 & 15 & 15 \\
\hline & 22012 & 23 & 23 & 23 & 23 & 23 & 23 \\
\hline & 32011 & 15 & 15 & 15 & 15 & 15 & 15 \\
\hline & 32012 & 26 & 26 & 26 & 26 & 26 & 26 \\
\hline & 42011 & 18 & 18 & 18 & 18 & 18 & 18 \\
\hline & 42012 & 29 & 29 & 29 & 29 & 29 & 29 \\
\hline & 52011 & 21 & 21 & 21 & 21 & 21 & 21 \\
\hline & 52012 & 33 & 33 & 33 & 32 & 33 & 33 \\
\hline & 62011 & 22 & 22 & 22 & 22 & 22 & 22 \\
\hline & 62012 & 33 & 33 & 33 & 33 & 33 & 33 \\
\hline & 72011 & 22 & 22 & 22 & 22 & 22 & 22 \\
\hline & 72012 & 33 & 33 & 33 & 33 & 33 & 33 \\
\hline & 82011 & 22 & 21 & 21 & 21 & 21 & 21 \\
\hline & 92012 & 33 & 20 & 10 & 33 & 33 & 33 \\
\hline & 92011 & 22 & 21 & 21 & 21 & 21 & 21 \\
\hline & 102011 & 22 & 20 & 20 & 20 & 20 & 19 \\
\hline
\end{tabular}


Table 5. Effect of type of lactation on the daily milk yield traits, LS-means \pm SE

\begin{tabular}{|c|c|c|c|c|c|}
\hline $\begin{array}{c}\text { Typ } \\
\mathrm{e}\end{array}$ & $\begin{array}{c}\text { Milk } \\
\text { morning }\end{array}$ & Milk midday & Milk evening & Milk daily & Fat, \% \\
\hline 11 & $0.484 \pm 0.046$ & $0.367 \pm 0.030$ & $0.323 \pm 0.035$ & $1.145 \pm 0091$ & $7.596 \pm 0.206$ \\
\hline 21 & $0.584 \pm 0.022$ & $0.387 \pm 0.014$ & $0.396 \pm 0.017$ & $1.338 \pm 0.043$ & $7.650 \pm 0.098$ \\
\hline 22 & $0.713 \pm 0.053$ & $0.463 \pm 0.035$ & $0.459 \pm 0.041$ & $1.595 \pm 0.106$ & $7.515 \pm 0.241$ \\
\hline
\end{tabular}

According to Dimov (1986) there are three types of lactation curves in dairy breed of sheep: first type, when maximal daily milk yield is measured after the first test, so called. "Cow type", second type, when maximal daily milk yield is measured during first milk test and third type, when during lactation appears second pik value.

Influence of number of milk test

The effect of number of milk test actually shows the stage of lactation. According to most previous examinations in dairy breed of sheep, the average daily milk yield reduces from the beginning to the end of lactation. The decrease was clear and significant for each of the four traits of milk yield (Table 6).

Table 6. Effect of consecutive test day on the daily milk yield traits, LS-means \pm SE

\begin{tabular}{|c|c|c|c|c|c|}
\hline $\begin{array}{c}\mathrm{T} \\
\mathrm{D}\end{array}$ & $\begin{array}{c}\text { Milk } \\
\text { morning }\end{array}$ & Milk midday & Milk evening & Milk daily & Fat, \% \\
\hline 1 & $0.781 \pm 0.048$ & $0.520 \pm 0.031$ & $0.540 \pm 0.037$ & $1.848 \pm 0.097$ & $7.511 \pm 0.219$ \\
\hline 2 & $0.740 \pm 0.043$ & $0.519 \pm 0.028$ & $0.495 \pm 0.033$ & $1.755 \pm 0.086$ & $7.507 \pm 0.194$ \\
\hline 3 & $0.686 \pm 0.039$ & $0.490 \pm 0.026$ & $0.444 \pm 0.031$ & $1.613 \pm 0.079$ & $7.388 \pm 0.179$ \\
\hline 4 & $0.604 \pm 0.037$ & $0.435 \pm 0.024$ & $0.433 \pm 0.029$ & $1.483 \pm 0.076$ & $7.365 \pm 0.171$ \\
\hline 5 & $0.570 \pm 0.039$ & $0.397 \pm 0.026$ & $0.374 \pm 0.030$ & $1.328 \pm 0.078$ & $7.642 \pm 0.178$ \\
\hline 6 & $0.534 \pm 0.042$ & $0.348 \pm 0.029$ & $0.330 \pm 0.033$ & $1.176 \pm 0.085$ & $7.802 \pm 0.193$ \\
\hline 7 & $0.494 \pm 0.052$ & $0.344 \pm 0.034$ & $0.336 \pm 0.038$ & $1.071 \pm 0.097$ & $7.912 \pm 0.220$ \\
\hline 8 & $0.519 \pm 0.068$ & $0.300 \pm 0.050$ & $0.308 \pm 0.049$ & $1.043 \pm 0.127$ & $7.642 \pm 0.289$ \\
\hline 9 & $0.415 \pm 0.091$ & $0.297 \pm 0.059$ & $0.274 \pm 0.071$ & $0.915 \pm 0.184$ & $7.515 \pm 0.423$ \\
\hline
\end{tabular}

Having in mind that daily milk yield continuously decreases, at the end of lactation keeps a level of around one liter. This trait is very important and characterizes these sheep as typical dairy type, with strong genetic potential for milk production in an extended period. In most examinations of local breed of dairy sheep, the period of lactation is significantly shorter and the milk yield reaches 0.2-0.3 1 at the end of lactation (Astruc et al., 2000, Astruc et al., 2002).

The percentage of fat content also varies throughout the lactation period, but no particular dependence was determined because the influence was insignificant (Table 2). Certain change in reducing the percentage of milk fat from $7.5 \%$ in the first to 7.4 in third and fourth test, with an increase in the 
following controls to 7.8 or $7.9 \%$ and re-reduction at last tests is difficult to explain and predict.

In other examinations, the expected tendency of this trait is increase of the percentage of milk fat by reducing the milk yield (Baldi et al., 1999).

The maintenance of constant and stable rate of milk fat during lactation characterizes these sheep as quite suitable for production of dairy products with a constant quality. Pacinovski et al. (2014) also found significant influence of number of milk test on above mentioned traits (morning, afternoon and evening milk) in Awassi breed of sheep.

\section{Influence of number of newborn lambs}

Most of the examined sheep in the flock had one lamb. The results of the analyses showed that during morning milking, sheep with two lambs had higher milk yield in comparison with sheep with one lamb (Table 7). This tendency was opposite during afternoon and evening milking.

Table 7. Effect of number of lambs born on the daily milk yield traits, LS-means \pm SE

\begin{tabular}{|c|c|c|c|c|c|}
\hline No & Milk morning & Milk midday & Milk evening & Milk daily & Fat, $\%$ \\
\hline 1 & $0.573 \pm 0.027$ & $0.423 \pm 0.018$ & $0.402 \pm 0.021$ & $1.358 \pm 0054$ & $7.596 \pm 0.122$ \\
\hline 2 & $0.615 \pm 0.034$ & $0.388 \pm 0.022$ & $0.383 \pm 0.026$ & $1.361 \pm 0068$ & $7.578 \pm 0.154$ \\
\hline
\end{tabular}

As an effect, the number of newborn lambs per sheep was insignificant for all five traits (Table 2). Therefore it is natural to expect that the milk production will not depend on this trait and we consider that this factor is not necessary to be included in further genetic studies.

Unlike these examinations, Pacinovski et al. (2014) determined significant influence of number of newborn lambs on some of above mentioned traits (evening and total amount of milk, total amount of fat), but on other traits (morning, afternoon milk), this factor had no influence at all.

\section{Influence of month of milk test}

In complex models of the factor of milk test, data for average differences in various stages of lactation is expected to be provided, having in mind that the last influence is seen from another factor during examination. At the same time, despite this, certain influence of these two factors may be possible.

The significant influence of month in the year shows that this factor should be included in all studies in order to obtain accurate evaluation for other effects which also represent an interest to be studied (Table 2). The evaluation of certain months show that certain increase of daily milk yield can be expected during June and July for morning and evening milking, due to better pasture conditions, but the results for total daily milk yield do not confirm this hypothesis.

Generally, when considering milk production from individual milking (morning, afternoon and evening), during individual years, some changes between individual months may be observed, but summarizing total daily milk yield 
seems to limit that influence (Table 8). Therefore, these analyses derive two conclusions. The first is, if the selection is bases on better record and correction of average effects then measurements of milk yield for certain periods - periods of test day, should represent individual indications or traits.

Table 8. Effect of month of test on the daily milk yield traits, LS-means \pm SE

\begin{tabular}{|c|c|c|c|c|c|}
\hline MY Test & Milk morning & Milk midday & Milk evening & Milk daily & Fat, \% \\
\hline 22011 & $0.580 \pm 0.072$ & $0.489 \pm 0.046$ & $0.365 \pm 0.056$ & $1.397 \pm 0.145$ & $7.427 \pm 0.328$ \\
\hline 32011 & $0.603 \pm 0.066$ & $0.475 \pm 0.043$ & $0.416 \pm 0.052$ & $1.462 \pm 0.134$ & $6.598 \pm 0.303$ \\
\hline 42011 & $0.525 \pm 0.059$ & $0.404 \pm 0.038$ & $0.464 \pm 0.046$ & $1.366 \pm 0.119$ & $7.037 \pm 0.270$ \\
\hline 52011 & $0.509 \pm 0.053$ & $0.387 \pm 0.035$ & $0.385 \pm 0.042$ & $1.242 \pm 0.107$ & $8.838 \pm 0.244$ \\
\hline 62011 & $0.473 \pm 0.051$ & $0.366 \pm 0.033$ & $0.420 \pm 0.040$ & $1.239 \pm 0.103$ & $7.897 \pm 0.234$ \\
\hline 72011 & $0.575 \pm 0.051$ & $0.301 \pm 0.033$ & $0.312 \pm 0.040$ & $1.182 \pm 0.103$ & $8.185 \pm 0.234$ \\
\hline 82011 & $0.454 \pm 0.055$ & $0.286 \pm 0.036$ & $0.274 \pm 0.042$ & $1.054 \pm 0.108$ & $8.106 \pm 0.244$ \\
\hline 102011 & $0.337 \pm 0.073$ & $0.229 \pm 0.047$ & $0.218 \pm 0.057$ & $0.822 \pm 0.146$ & $8.843 \pm 0.331$ \\
\hline 12012 & $0.872 \pm 0.080$ & $0.518 \pm 0.052$ & $0.666 \pm 0.062$ & $2.015 \pm 0.161$ & $8.134 \pm 0.365$ \\
\hline 22012 & $0.799 \pm 0.057$ & $0.584 \pm 0.037$ & $0.455 \pm 0.044$ & $1.804 \pm 0.114$ & $5.767 \pm 0.258$ \\
\hline 32012 & $0.790 \pm 0.050$ & $0.583 \pm 0.032$ & $0.345 \pm 0.039$ & $1.690 \pm 0.100$ & $7.785 \pm 0.227$ \\
\hline 42012 & $0.861 \pm 0.045$ & $0.409 \pm 0.029$ & $0.378 \pm 0.035$ & $1.618 \pm 0.091$ & $6.948 \pm 0.207$ \\
\hline 52012 & $0.833 \pm 0.042$ & $0.399 \pm 0.028$ & $0.360 \pm 0.033$ & $1.548 \pm 0.085$ & $6.512 \pm 0.193$ \\
\hline 62012 & $0.570 \pm 0.042$ & $0.378 \pm 0.028$ & $0.450 \pm 0.033$ & $1.383 \pm 0.085$ & $8.519 \pm 0.194$ \\
\hline 72012 & $0.492 \pm 0.044$ & $0.384 \pm 0.029$ & $0.401 \pm 0.034$ & $1.293 \pm 0.088$ & $8.578 \pm 0.200$ \\
\hline 92012 & $0.492 \pm 0.053$ & $0.428 \pm 0.044$ & $0.497 \pm 0.037$ & $1.083 \pm 0.097$ & $5.279 \pm 0.219$ \\
\hline
\end{tabular}

The second one is that the type - model for genetic evaluations, which is based on milk yield of separate milking during the test day, has not yet been discussed in literature. Pacinovski et al. (2014) determined significant influence of month of milk test on above mentioned traits (morning, afternoon and evening milk) in Awassi sheep and similar results obtained Alkass et al., (2008) in Awassi sheep in Iraq. More detailed studies and gathering more information will be necessary in future to compare with the model of daily milk yield, as correlations and genetic relations between individual measurements of milk production during the test day.

\section{CONCLUSIONS}

The milk yield of sheep from recognized organizations of Awassi breeders or so called Breeding organization for Awassi, during individual test days depends significantly on the number of lactation or age, number of test and month i.e. year.

Milk yield is at certain high level to seventh lactation i.e. to an age of 9 . Sheep are with long milking period from 8-9 tests or months (240-270 days), with suckling period of around 60 days. 
Changes in daily milk yield, affected by environmental factors, are more noticeable during individual measurements of the test day (morning, afternoon and evening milk), compared to total daily milk yield in the same day.

\section{REFERENCES}

Astruc, M. J., Barillet, F., Klopcic, M., Malinger, K., Siard, N. 2000. Report of the Working Group on Milk Recording of Sheep. Proceedings of the 32rd Biennial Session of ICAR. May 14-19, Bled, Slovenia. pp. 1-15

Astruc, M. J., Barillet, F., Fioretti, M., Gabina, D., Gootwine, E., Mavrogenis, P. A., Romberg, J. F., Sanna, R. S. \& Stefanake, E. 2002. Report of the Working Group on Milk Recording of Sheep. Proceedings of the 33rd Biennial Session of ICAR. May 26-31, Interlaken, Switzerland, pp. 1-10.

Alkass J. E., Al-Rawi A. A., Al-Mohammadi D. S. H. 2008. Evaluation of test-day milk yield in some commercial Awassi sheep flocks. Egyptian Journal of Sheep and Goat Sciences, Vol. 3, No. 2, pp. 19-26.

Baldi, A., Chiofalo, V., Savoini, G., Pinotti, L., Politis, I. 1999. Milk quality in dairy ewes at the end of lactation. Milking and milk production of dairy sheep and goats. Proceedings of the Sixth International Symposium on the milking of small ruminants, September 26 - October 1, 1998, Athens, Greece. pp. 134-147

Dimov G. 1986. Types of lactation curves in Pleven blackhead ewes. Proceedings of the III International conference in genetics. Varna, Bulgaria. pp. 373-376.

Pacinovski N., Eftimova Elena, Mateva Natasa, Palasevski B., Cilev G., Adamov N. 2014. Influence of some factors on daily milk production in Awassi breed of sheep in Macedonia. Macedonian Journal of Animal Science, Vol. 4, No. 1, pp. $1-9$. 